\title{
ZWISCHEN LATEINISCHEM WESTEN UND CHRISTLICHEM OSTEN: NOCH EINMAL ZUR CHRISTIANISIERUNG DER RUS
}

\author{
DANA PICKOVÁ \\ Philosophische Fakultät, Karls-Universität, Prag \\ E-mail: dana.pickova@ff.cuni.cz
}

\begin{abstract}
Between the Latin West and the Christian East: Once Again to the Christianisation of Rus'

Christianization of the Rus' is a subject of many existing articles and monographs. This article however deals it again from a somewhat untraditional perspective. It stresses the possible influence not only the center of Eastern Christianity, the Byzantine Empire, but also the centers representing the Western Christianity, that is, the Roman Empire and the Papacy had on this process. At the same time, a certain parallel between the events surrounding the Cyril and Methodius's mission, the acceptance of Christianity in Bulgary and the Christianization of the Rus' is pointed out.

Keywords: Christianization; Rus'; Orthodox Christianity; Latin Christendom; 9th-10th century
\end{abstract}

Man schrieb das Jahr 862 und Fürst Rastislav, Herrscher des bedeutendsten Staatsgebildes der Westslawen, bereitete eine Abordnung zum byzantinischen Kaiser Michael III. vor, um ihn um Entsendung eines Bischofs und eines Lehrers zu bitten. Er wünschte sich nicht nur, dass sein Volk tiefere Belehrung zum Glauben erfährt, sondern strebte auch nach Errichtung einer selbstständigen Kirchenorganisation, die die Gefahr abwenden würde, dass Mähren in Kirchenfragen dem fränkischen Episkopat untergeordnet wird. Es drohte nämlich, dass der ostfränkische König Ludwig II. der Deutsche dies zugleich zur politischen Unterwerfung Mährens ausnutzen könnte. Dies bemüht sich Rastislav zu verhindern, sowohl militärisch als auch durch seine Anstrengungen, ein eigenes Bistum einzurichten ${ }^{1}$. Als er im päpstlichen Rom kein Gehör fand, wandte er seine Aufmerksamkeit Konstantinopel zu, denn der dortige Patriarch, der sich unter dem Schutz des Kaisers selbst befand, konnte seiner Bitte entsprechen, auch wenn dies ungewöhnlich war. Es ist jedoch allgemein bekannt, dass es nicht dazu kam und dass alles anders ausging.

Das Byzantinische Reich stand zu dieser Zeit am Beginn seiner höchsten Machtentfaltung, die bis in die zwanziger Jahre des 11. Jahrhunderts andauerte. Nach nicht enden wollenden Jahren der Streitigkeiten um die Bilderverehrung kehrte das Reich offiziell zur Ikonodulie zurück und eine gewisse innere Stabilität und der wirtschaftliche Aufstieg ermöglichten ihm danach, eine mächtige Offensive zu starten und das von Byzanz be-

1 Vladimír VAVŘínEK, Cyril a Metoděj mezi Konstantinopolí a Římem. Praha 2013, S. 114 f. 
herrschte Territorium fast bis zu den Grenzen des ursprünglichen römischen Imperiums zu erweitern. Dies ging jedoch nicht ohne häufige Konflikte mit dem mächtigen Reich der Bulgaren ab, das sich im 9. und zu Beginn des 10. Jahrhunderts dynamisch auf dem Gebiet des Balkans entwickelte, der einst zum römischen Reich gehört hatte. Auch in Bulgarien befasste man sich zu dieser Zeit mit der Frage, von wo man das Christentum annehmen soll, beziehungsweise wie man eine selbstständige Kirchenorganisation erlangen soll.

Die Geschichte des bulgarischen Khans Boris I. ist eine gewisse Analogie dessen, was sich in Mähren abspielte, hat jedoch ihre Spezifika und ist etwas verworrener. Auf dem Gebiet des sich konstituierenden slawisch-bulgarischen Staates war ein Teil der ursprünglich römischen Bevölkerung verblieben, die sich zum Christentum bekannten. Weitere Christen, die sich auf seinem Gebiet bewegten, waren Kaufleute und vor allem zahlreiche Kriegsgefangene. Diese konnten nicht nur den neuen Glauben verbreiten, sondern auch den kulturellen und politischen Einfluss von Byzanz. Daher ist es kein Wunder, dass die bulgarischen Herrscher bemüht waren, mit allen Mitteln eine Christianisierung zu verhindern, und zwar sogar mit Hinrichtungen von Kriegsgefangenen. Trotzdem drang das Christentum allmählich auch in die höchsten Schichten vor. Im Jahr 833 hatte Khan Malamir seinen älteren Bruder Enravot hinrichten lassen, weil er Christ war und es ablehnte, seinem Glauben zu entsagen. Es dauerte jedoch noch zwei Generationen, bevor Khan Boris I. zu der Ansicht kam, dass Bulgarien sich nicht der Annahme des Christentums verweigern sollte. Die Taufe sollten ihm fränkische Missionare vermitteln, die damals im Land tätig waren. Dies war eine Folge des Bündnisvertrags, den Boris mit Ludwig dem Deutschen gegen den mährischen Rastislav geschlossen hatte und der wiederum zu Rastislavs Entscheidung beigetragen haben mochte, eine Gesandtschaft nach Byzanz zu entsenden.

Zur Annahme des westlichen Christentums durch die Bulgaren kam es schließlich nicht. Beziehungsweise bevor es zu ihr kommen konnte, fielen byzantinische Truppen in Bulgarien ein. Der Khan schloss im Bemühen, eine Plünderung seines Landes zu verhindern, mit den Byzantinern Frieden und nahm im Jahr 865 vom byzantinischen Reich das Christentum an. Zugleich versuchte er, die kirchliche Selbstständigkeit des bulgarischen Staates zu sichern und ersuchte um die Einrichtung einer gesonderten Kirchenprovinz mit einem Patriarchen und Bischöfen an der Spitze. Dies versagte ihm jedoch der Patriarch von Konstantinopel Photios. Der Khan verwies daher bereits 866 die griechischen Geistlichen seines Landes und ersuchte den ostfränkischen König Ludwig den Deutschen um Missionare. Zugleich wandte er sich an den Papst Nikolaus I. mit der Bitte, ihm einen Patriarchen und Bischöfe zu senden.

Diese Bitte begeisterte den Papst, denn sie bot ihm die Möglichkeit, das Gebiet Illyrien erneut unter römische Oberherrschaft zu bringen, um das er gerade Streit mit Byzanz führte. Sofort erklärte er, dass Bulgarien ausschließlich unter die Jurisdiktion der päpstlichen Kurie fällt und wies die ostfränkischen Priester an, die Ludwig der Deutsche bereits hierher entsenden konnte, das Land zu verlassen. Dann entsandte er nach Bulgarien selbst Missionare mit zwei Bischöfen an der Spitze, die die Aufgabe hatten, sich um die Organisation der jungen bulgarischen Kirche zu kümmern. In Bulgarien ein Patriarchat einzurichten, beabsichtigte er jedoch entschieden nicht, denn - wie er Boris erläuterte Patriarchate gibt es nur drei (in Rom, Antiochien und Alexandria) und sie leiten ihren 
Ursprung vom Wirken der Apostel selbst ab. Trotzdem sagte er zu, dass hier ein Erzbistum gebildet wird, sobald der neue Glauben in Bulgarien festere Positionen erlangt und ausreichend Gläubige hat. Darauf wartete Boris jedoch sowohl bei Nikolaus I. als auch bei dessen Nachfolger Hadrian II. vergebens, obwohl er bei beiden sehr darauf drang. Wahrscheinlich brachte dies ihn dazu, sich erneut an Byzanz zu wenden.

Ende 869 berief Kaiser Basileios I. ein Konzil nach Konstantinopel ein, das die Streitigkeiten zwischen Byzanz und der päpstlichen Kurie, die unter Photios' Patriarchat entbrannt waren, beilegen sollte. Unmittelbar nach seiner offiziellen Beendigung fanden sich bulgarische Gesandte mit der Frage ein, die ihren Herrscher Boris so beschäftigte: gehört Bulgarien unter die kirchliche Jurisdiktion des römischen Papstes oder des Patriarchen von Konstantinopel? Der Kaiser nutzte die Gelegenheit und ließ den Streit durch unparteiische Schiedsrichter entscheiden, für die er die Vertreter der östlichen Patriarchen ansah. Der Schiedsspruch lautete zugunsten von Konstantinopel. Diese Lösung sagte auch Boris zu. Insbesondere als Patriarch Ignatios, zweifellos belehrt durch die vorhergehende Entwicklung der Ereignisse, endlich einen bulgarischen Metropoliten und mehrere Bischöfe einsetzte. Die griechischen Geistlichen kehrten nach Bulgarien zurück, und deshalb nahm Boris I. später gern in Bulgarien die aus Mähren vertriebenen Schüler Methods auf, in denen er ein mögliches Gegengewicht zur Verbreitung des byzantinischen Einflusses sah².

Im Unterschied zu Mittel- und Südosteuropa gab es Mitte des 9. Jahrhunderts in den Ebenen Osteuropas, die ebenfalls von slawischer Bevölkerung besiedelt waren, bis jetzt keinen Staat und die hiesige Bevölkerung hatte kaum einen Begriff vom christlichen Glauben. Die Frage, ob und von wo den christlichen Glauben annehmen, kam etwas später auf die Tagungsordnung, in der zweiten Hälfte des 10. Jahrhunderts, als sich hier eine deutlichere staatliche Organisation mit Zentrum in Kiew zu bilden begann. Die hiesigen Herrscher leisteten jedoch der Annahme des Christentums relativ lange Widerstand, ebenso wie die bulgarischen Herrscher. Der Grund waren in diesem Fall wohl nicht in erster Linie Befürchtungen vor dem Vordringen eines zu starken byzantinischer Einflusses, sondern vor allem der Umstand, dass die russische Elite noch nicht auf eine Christianisierung vorbereitet war und lange den heidnischen Kulten diente ${ }^{3}$, so dass anfangs nur Privatpersonen die Taufe annahmen.

Der Christianisierung der Rus wurden bereits zahlreiche Abhandlungen und Monografien gewidmet, trotzdem komme ich noch einmal auf dieses Thema zurück. Jedoch möchte ich mich mit ihm etwas nicht traditionell befassen, und zwar vom Gesichtspunkt des Einflusses, das auf diesen Prozess die Zentren des Christentums nahmen, also nicht nur der orthodoxe Osten, sondern auch der katholische Westen, das heißt das byzantini-

2 Boris' kompliziertes Lavieren zwischen Konstantinopel, Rom und zugleich auch dem ostfränkischen König sowie dessen Beziehungen zu den Ereignissen um die Mission von Kyrill und Method schilderte Vavř́nek sehr übersichtlich in seiner letzten Arbeit mit dem passenden Titel Kyrill und Method zwischen Konstantinopel und Rom. VAVŘínEK, Cyril a Metoděj, S. 47 f., 142-147, 190, 192 ff. Siehe auch Геннадий Григорьевич ЛИТАВРИН, Древняя Русь, Византия и Болгария в IX-X вв. Москва 1983, с. 30-67 (Gennadii Grigor'evich LITAVRIN, Drevnyaya Rus', Vizantiya i Bolgariya $v$ IX-X vv. Moskva 1983, S. 30-67) oder Lutz E. von PADBERG, Christianisierung im Mittelalter. Darmstadt 2006, S. 127-130.

3 Andrzej POPPE, The Political Background to the Baptism of Rus': Byzantine-Russian Relations between 986-989, in: Dumbarton Oaks Papers 30 (1976), S. 243. 
sche Reich sowie das westliche Kaiserreich und der Papst. Zugleich möchte ich auf eine gewisse Parallele zwischen den Ereignissen verweisen, die sich um die Mission von Kyrill und Method und die Annahme des Christentums in Bulgarien und ein Jahrhundert später in der Kiewer Rus abspielten.

Das Christentum drang allmählich und in mehreren Wellen in die Rus vor ${ }^{4}$. Abgesehen von der sog. Andreaslegende, die in der Nestorchronik (Povest'vremennykh let, Erzählung der vergangenen Jahre) wiedergegeben wird und erzählt, dass der erste Christ, der eine Reise nach Osteuropa unternahm, der Apostel Andreas selbst gewesen sei ${ }^{5}$, war der älteste reale Versuch einer Christianisierung der Rus mit der Missionstätigkeit des Patriarchen von Konstantinopel Photios verbunden. Es war wahrscheinlich der erste historisch belegte Überfall der Rus auf Konstantinopel im Jahr 860, der ihn auf den Gedanken brachte, sich der Missionsarbeit bei den heidnischen Feinden des Reichs zu widmen, und dies nicht nur bei den Rus, sondern vor allem bei den Bulgaren, und so aus ihnen Freunde oder direkt Verbündete zu machen. In einer Zeit, in der Byzanz bemüht war, seine Grenzen zu sichern und seinen Machteinfluss auch mit anderen als mit militärischen Mitteln zu vergrößern ${ }^{6}$, sollten christliche Missionen ein wichtiger Bestandteil ihrer Diplomatie werden. Die Annahme der Orthodoxie und der griechischen Bildung schuf eine ideologische Bindung des christianisierten Landes an das Ostreich und bereitete so die Bedingungen vor für seine Eingliederung in die Kirchenorganisation, an deren Spitze der Patriarch von Konstantinopel stand, und zugleich auch in die christliche Oikumene mit dem Kaiser von Byzanz an der Spitze.

Nach der späteren Auslegung des Fortsetzers des Chronisten Theophanes ${ }^{7}$ erschienen kurz nach diesem Überfall am kaiserlichen Hof in Konstantinopel Gesandte der Rus, die um ihre Taufe baten, und Photios ergriff die sich ihm bietende Gelegenheit. Meiner Meinung nach war es jedoch gerade umgekehrt und die Initiative zur ersten Christianisierung der Russen ging von Byzanz aus, und zwar vom Patriarchen selbst. Das geschah kurz, nachdem es den Byzantinern gelungen war, die Bulgaren zu christianisieren und auch kurz, nachdem die Mission zum Mährerreich entsandt worden war. Dies belegt die Enzyklika von 867, die Photios an alle östlichen Patriarchen sandte, und in der er unter anderem mitteilte, dass "nicht nur das ganze alte Volk [die Bulgaren] seine bisherige Gottlosigkeit gegen den Glauben an Christus getauscht hat, sondern auch das Volk, von dem wiederholt berichtet wird, dass es mit seiner Grausamkeit und Blutrünstigkeit alle

4 Ludolf MÜLLER, Die Taufe Russlands: die Frühgeschichte der russischen Christen bis zum Jahre 988. München 1987.

5 Дмитрий Сергеевич ЛИХАЧЕВ - Варвара Павловна АДРИАНОВА-ПЕРЕТЦ (сост.) Повесть временных лет. Санкт Петерсбург 1996, с. 9 (Dmitrii Sergeevich LIKHACHEV - Varvara Pavlovna ADRIANOVA-PERETTS [Hgg.], Povest' vremennykh let. Sankt Peterburg, 1996, S. 9). Weitergehende Informationen finden wir in diesen Artikeln: Лудольф МЮЛЛЕР, Древнрусское сказание о хождении апостола Андрея в Киев и Новгород, Борис Александрович РЫБАКОВ (сост.), в: Летописи и хроники. 1974, с. 48-64 (Ludol'f MYULLER, Drevnerusskoe skazanie o khozhdenii apostola Andreya v Kiev i Novgorod, in: Boris Aleksandrovich RYBAKOV [Hg.], Letopisi i khroniki 1974, S. 48-64); Аполлон Григорьевич КУЗЬМИН, Сказание об апостоле Андрее и его место в Началной летописи, в: РЫБАКОВ (сост.), Летописи и хроники, с. 37-47 (Apollon Grigorevich KUZ’MIN, Skazanie ob apostole Andree i ego mesto v Nachal'noi letopisi, in: RYBAKOV [Hg.], Letopisi i khroniki, S. 37-47).

6 MÜLLER, Die Taufe Russlands, S. 57.

7 Theopfanes Continuatus, in: Jacques-Paul MIGNE (Hg.), Patrologia Graeca. Bd. 109. Paris 1863, col. 209-212. 
anderen übertrifft, und das Rhós heißt" ${ }^{\text {"8 }}$. Der Patriarch von Konstantinopel schrieb ferner, dass die Rus sogar einen eigenen Bischof hätten, das heißt eine Kirchenorganisation. Sein Schreiben enthält jedoch keine Angaben darüber, wie ihre Christianisierung verlaufen ist, wer sie initiiert hatte und wenn er in diesem Fall mit dem Begriff Rus bezeichnete.

Die Taufe empfing zweifellos vor allem die herrschende Garnitur, im betreffenden Fall höchstwahrscheinlich der Kiewer Fürst mit seinem Gefolge. Die ältesten russischen Annalen - die Nestorchronik - bezeichnet als damaligen Herrscher von Kiew die WarägerAnführer Askold und Dir, mit denen sie auch den ersten russischen Angriff auf Konstantinopel verbindet. Die Chronik berichtet von ihnen als Christen. Nach der Nestorchronik wurde über Askolds Grab die St.-Nikolaus-Kirche erbaut, während Dir, später in der Rus als Märtyrer verehrt, seine letzte Ruhestätte bei der Irenenkirche fand ${ }^{9}$. Wenn Askold und Dir tatsächlich gelebt und geherrscht haben, konnten es gerade sie gewesen sein, die von durch Photios entsandten byzantinischen Missionaren getauft wurden. Auf jeden Fall können wir konstatieren, dass der Patriarch von Konstantinopel Photios sich in den sechziger Jahren des 9. Jahrhunderts darum verdient machte, dass das Christentum vom "Volk, das Rhós heißt" angenommen wurde, und dass es sich am ehesten um schwedische Waräger handelte, die sich im osteuropäischen Raum bewegten.

Diese erste Christianisierungsetappe der Rus war der Nestorchronik zufolge nur eine Episode, denn Askold und Dir kamen in dem Augenblick um, als Oleg, ein weiterer halblegendärer Waräger-Anführer, Kiew einnahm ${ }^{10}$. Die Verbreitung des Christentums in Kiew wurde so gestoppt, denn Oleg war Heide. Die unlängst gegründete Kirchenorganisation ging offenbar mitsamt dem Bistum unter. Ohne Rücksicht auf konkrete Personen, deren Existenz wir nicht belegen können, kam es bald nach der ersten Christianisierung in Kiew zu einem Machtwechsel, dem die hiesigen christlichen Herrscher zum Opfer fielen.

Das Christentum wurde jedoch nicht völlig unterdrückt. Im Unterschied zu den anderen Phasen zeichnete sich die zweite durch keine wichtigen Ereignisse aus und war nicht mit der Taufe eines Herrschers oder einer anderen bedeutenden Persönlichkeit verbunden. Es war ein allmählicher Prozess. Bereits 911, als der erste uns bekannte russischbyzantinische Vertrag geschlossen wurde, widmete Kaiser Leo VI. Olegs Gesandten Reliquien und wies an, sie mit dem christlichen Glaubensbekenntnis vertraut zu machen ${ }^{11}$. Bei Handelsreisen und Kriegszügen nach Byzanz trafen die Rus immer wieder auf den christlichen Glauben und einige von ihnen nahmen ihn auch an ${ }^{12}$. Das Christentum begann so, in die Rus zu einem bestimmten Bevölkerungskreis vorzudringen. Es muss jedoch konstatiert werden, dass es sich nicht nur um das östliche Christentum handelte. Einige der warägischen Kaufleute, fassungslos angesichts der Herrlichkeit Konstantinopels und des Prunks der hiesigen Gotteshäuser, empfingen hier zweifellos die Taufe, andere jedoch - wenn auch in geringerem Maß - wurden wohl bereits in Schweden

8 Encyklika epistola ad archiepiscopales thronos per Orientem obtinentes, in: Jacques-Paul MIGNE (Hg.), Patrologia Graeca. Bd. 102. Turnholt 1900, col. 735-738.

9 Повесть временных лет, с. 14 (Povest'vremennykh let, S. 14).

10 Ebd., S. 14.

11 Ebd., S. 17.

12 Jonathan SHEPARD, Rus', in: Nora Berend (Hg.), Christianization and the Rise of Christian Monarchy: Scandinavia, Central Europe and Rus' c.900-1200. Cambridge 2007, S. 375, 377. 
getauft $^{13}$, doch dort setzte sich der neue Glauben ebenso schleppend durch wie in der Rus $^{14}$. Ein Beleg dafür, dass ein Teil der Waräger und vielleicht auch der Slawen bereits Mitte des 10. Jahrhunderts Christen waren, ist der russisch-byzantinische Vertrag von 944, dessen Text wir wiederum nur aus der Nestorchronik kennen. Während Fürst Igor und jene seiner Abgesandten, die gerade vom Hof in Konstantinopel zurückgekehrt waren und Heiden waren, auf den Vertrag bei einem Idol des Perun schworen, leisteten die christlichen Abgesandten ihren Eid in der Kiewer St.-Elias-Kirche. So informiert uns der Chronist nicht nur darüber, dass Mitte des 10. Jahrhunderts viele Waräger Christen waren, sondern zugleich, dass in Kiew zu dieser Zeit eine Kirche stand, die dem Propheten Elias geweiht war ${ }^{15}$, der einen wichtigen Platz unter jenen Heiligen einnahm, die in frühchristlichen Zeiten von den slawischen Völkern verehrt wurden. Interessant ist, dass in der Nestorchronik die Eliaskirche als „sobornaja cerkov“ bezeichnet wird, was bedeuten würde, dass es sich um die Hauptkirche in der Stadt handelte, dass es also noch weitere christliche Gotteshäuser gab ${ }^{16}$. Der arabische Reisende und Schriftsteller Al-Masudi schrieb Anfang der vierziger Jahre des 10. Jahrhunderts in seinem ausführlichen Werk Akhbar az-Zaman, dass die Slawen sich zum Heidentum wie zum Christentum bekennen, jedoch die meisten Heiden seien ${ }^{17}$.

Die dritte Christianisierungsetappe der Rus stellt die Taufe der Fürstin Olga dar, der Witwe von Fürst Igor, die in den Jahren 944 bis 962 als Regentin für ihren minderjährigen Sohn Swjatoslaw regierte. Obwohl es nur eine persönliche Tat war, nicht etwa die Christianisierung des ganzen Landes, erreichte so die allmähliche Verbreitung des Christentums in der Rus einen höheren Grad, denn es wurde eine herrschende Person getauft, der die bedeutende Rolle des ersten christlichen Herrschers auf dem russischen Thron zukam $^{18}$. Nach der in russischen (Nestorchronik ${ }^{19}$ ) und byzantinischen Quellen (Chronik des Johannes Skylitzes ${ }^{20}$ ) erhaltenen Tradition wurde Olga während ihres Aufenthalts am Kaiserhof in Konstantinopel getauft. Zu diesem Thema wird schon lange unter den Fachleuten diskutiert ${ }^{21}$. Persönlich neige ich zu der Ansicht, dass die Fürstin zwar die Taufe

13 Ebd., S. 375; Francis DVORNIK, Byzantine missions among the Slavs: SS. Constantine-Cyril and Methodius. New Brunswick, NJ 1970, S. 268; Владимир ДУХОПЕЛьНИКОВ, Крещение Руси. Харков 2009, c. 40 (Vladimir DUKHOPELNIKOV, Kreshchenie Rusi. Khar'kov 2009, S. 40).

14 Nils BLOMKVIST - Stefan BRINK - Thomas LINDKVIS, The kingdom of Sweden, in: Berend (Hg.), Christianization and the Rise of Christian Monarchy, S. 176-179.

15 Das Holzgebäude befand sich wahrscheinlich an der Stelle, wo heute eine aus dem 17. Jahrhundert stammende Kirche mit derselben Weihung steht, also im Kiewer Stadtviertel Podol, das von Kaufleuten und Handwerkern bewohnt war. Das Gebäude wurde jedoch archäologisch nicht nachgewiesen.

16 Повесть временных лет, с. 26 (Povest' vremennykh let, S. 26).

17 MASÚDÍ, Bericht über die Slaven, in: Peter Kawerau (Hg.), Arabische Quellen zur Christianisierung Rußlands. Wiesbaden 1967, S. 11 f. (arabisches Original und deutsche Übersetzung).

18 Dmitri OBOLENSKY, Russia and Byzantium in the Mid-Tenth Century: the Problem of Baptism of Princess Olga, in: The Greek Orthodox Theological Review 28/2 (1983), S. 157.

19 Повесть временных лет, с. 29-30 (Povest'vremennykh let, S. 29 f.).

20 Ioannis Scylitzae synopsis historiarum, hg. von Hans THURN (Corpus Fontium Historiae Byzantinae. Series Berolinensis. Bd. 5). Berlin/New York 1973, S. 240.

${ }^{21}$ Michael FEATHERSTONE, Olga's Visit to Constantinople in De Cerimoniis, in: Revue de Études Byzantines 61 (2003), S. 241-251; Геннадий Григорьевич ЛИТАВРИН, Византия Болгария, Древняя Русь (IX-начало XII в). Спб. 2000, с. 154-213 (Gennadii Grigor'evich LITAVRIN, Vizantiya, Bolgariya, Drevnyaya Rus' IX-nachalo XII v. Sankt-Peterburg 2000, S. 154-213); Andrzej POPPE, Once Again Concerning the Baptism of Olga, Archontissa of Rus', in: Anthony Cutler - Simon Franklin (Hgg.), Homo Byzantinus: Papers in Honor of Alexander Kazhdan. Washington, DC 1992, S. 271-277; Александр Васильевич НАЗАРЕНКО, Еще раз о дате 
nach dem östlichen Ritus empfing, jedoch aus den Händen eines einheimischen Priesters in $\mathrm{Kiew}^{22}$. Das Christentum in der Rus hatte sich während ihrer Herrschaft bereits zu einem gewissen Maß etabliert, wenn auch vorerst in der privaten Sphäre, so dass Olga mit ihm zweifellos gut bekannt war. Zur Vertiefung ihrer Kenntnisse konnte es während ihres Besuchs in Konstantinopel gekommen sein, wohin sich die Fürstin ganz am Anfang ihrer Herrschaftszeit im Jahr 946 begab $^{23}$. Die Audienz, die ihr damals am Kaiserhof gewährt wurde, ist in der Schrift De ceremoniis aulae Byzantinae ${ }^{24}$ beschrieben, die Kaiser Konstantin VII. Porphyrogennetos zusammenstellen ließ oder sogar selbst erstellte. Er empfing die russische Fürstin persönlich. Olga kam damals nicht nach Byzanz, um ihre Taufe zu erbitten - dies wird in dieser historischen Quelle nirgends erwähnt - sondern besprach am ehesten Angelegenheiten zum russisch-byzantinischen Vertrag, den kurz zuvor ihr verstorbener Gatte Fürst Igor geschlossen hatte ${ }^{25}$. Deshalb nahm sie nicht nur „ihre Leute“ und Verwandte mit, sondern auch Abgeordnete der russischen Fürsten und Kaufleute, die ein Interesse daran hatten, dass nach dem Tod von Fürst Igor und der Absetzung des byzantinischen Kaisers Romanos Lakapenos die von diesen Herrschern vereinbarten günstigen Bedingungen für den Handel der Rus in Byzanz weiter eingehalten werden. Bei dieser Gelegenheit konnte am kaiserlichen Hof der Fürstin angedeutet worden sein, sie möge sich taufen lassen, so wie dies vor vielen Jahren den Abgeordneten des Kiewer Herrschers Oleg vermittels einer Belehrung über den Glauben angedeutet worden war.

Eine gewisse Zeit nach ihrer Rückkehr aus Byzanz kam Olga zu der Ansicht, dass sie sich wirklich taufen lässt. In Kiew gab es mindestens eine Kirche, das heißt, es musste hier Priester geben, die diese Zeremonie vornehmen konnten. Erst die spätere Legende, die im 11. Jahrhundert verfasst wurde ${ }^{26}$, als in der Rus bereits eine selbstständige Kir-

поездки княгини Ольги в Константинополь: Источниковедческие заметки, в: Древнейшие государства Восточной Европы. Москва 1995, с. 154-168 (Aleksandr Vasilevich NAZARENKO, Eshche raz o date poezdki knyagini Olgi v Konstantinopol: Istochnikovedcheskie zametki, in: Drevneishie gosudarstva Vostochnoi Evropy. Moskva 1994, S. 154-168); Александр Васильевич НАЗАРЕНКО, Когда же княгиня Ольга ездила в Константинополь, в: Византийский временник 50 (1989), c. 66-83 (Aleksandr Vasilevich NAZARENKO, Kogda zhe knyaginya Olga ezdila v Konstantinopol, in: Vizantiiskii vremennik, 50 (1989), S. 66-83); Omeljan PRITSAK, When and Where Was Olga Baptized, in: Harvard Ukrainian Studies 9/1-2 (1985), S. 5-24; OBOLENSKY, Russia and Byzantium S. 157-171 u. a.

22 Георгий Александрович ОСТРОГОРСКИЙ, Византия и киевская княгиня Ольга (Georgii Aleksandrovich OSTROGORSKII, Vizantiya i kievskaya knyaginya Olga), in: To Honor of Roman Jakobson. Bd. 2. Hague/Paris 1967, S. 1458; siehe auch DVORNIK, Byzantine missions among the Slavs, S. 268 f.; Hartmut RÜSS, Das Reich von Kiev, in: Manfred Hellmann - Gottfried Schramm - Klaus Zernack (Hgg.), Handbuch der Geschichte Russlands. 1. Bd: Bis 1613 von der Kiever Reichsbildung bis zum Moskauer Zartum. Stuttgart 1981, S. 292 f.; Manfred HELLMANN, Westeuropäische Kontakte der Alten Rus', in: Gerhard Bikrfellner (Hg.), Millenium Russiae Christianae: Tausend Jahre Christliches Rußland 988-1988. München/Wien 1993, S. 87. Auch OBOLENSKY, Russia and Byzantium lehnt die Behauptung ab, dass Olga in Konstantinopel getauft wurde, als Datum des Besuchs gibt er jedoch das Jahr 957 an.

23 ЛИТАВРИН, Византия Болгария, Древняя Русь, с. 175-191 (LITAVRIN, Vizantiya, Bolgariya, Drevnyaya Rus', S. 175-191).

24 Constantini Porphyrogeniti De cerimoniis aulae Byzantinae, in: Jacques-Paul MIGNE (Hg.), Patrologia Graeca. Bd. 112. Turnholt 1897, col. 1047-1054.

25 Siehe auch Владимир Терентьевыс̌ ПАШУТО, Внешная политика Древней Руси. Москва 1968, c. 66 (Vladimir Terent'evich PASHUTO, Vneshnyaya politika Drevnei Rusi. Moskva 1968, S. 66).

26 Beide Hauptquellen, die die Taufe von Fürstin Olga mit ihrem Besuch in Konstantinopel verbinden, entstanden erst, nachdem diese Legende geschaffen wurde. Johannes Skylitzes schrieb seine Chronik 
chenorganisation bestand, die verehrungswürdige, aus dem heimischen Herrscherhaus stammende Heilige benötigte, verband die Taufe der Fürstin Olga, der ersten russischen christlichen Herrscherin, mit ihrem Besuch in Konstantinopel. Dies verlieh ihrer Taufe eine besondere Bedeutung, denn dieser Auslegung zufolge wurde sie nicht von einem bedeutungslosen Kiewer Priester getauft, sondern vom Patriarchen von Konstantinopel und in der Rolle des Taufpaten trat dabei der byzantinische Kaiser selbst auf.

In diesem Fall führte die Taufe des Herrschers nicht zur Christianisierung des Landes, wie dies in Zeiten des frühen Christentums üblich war. Der neue Glaube hatte zwar bereits im Kreis des fürstlichen Gefolges eine gewisse Anzahl Vertreter gewonnen, ansonsten hätte sich die Fürstin nicht taufen lassen ${ }^{27}$, doch waren die Verfechter des Heidentums noch in der Überzahl. Unter ihrem Einfluss befanden sich zweifellos Olgas Sohn Swjatoslaw, der eine Annahme des Christentums strikt ablehnte ${ }^{28}$, und anfangs dann auch dessen Sohn Wladimir Swjatoslawitsch. Einer der Gründe der negativen Einstellung der Elite konnte die Befürchtung gewesen sein, dass sich eine aus Byzanz christianisierte Rus dem mächtigen Reich nicht nur in kirchlicher Hinsicht unterordnet, sondern zugleich auch in politische Abhängigkeit von Konstantinopel gerät ${ }^{29}$. Dies wünschten sich die russischen Herrscherkreise sicher nicht, obwohl ihnen der Handel mit Byzanz erhebliche Gewinne einbrachte. Die besonnene Herrscherin, die ihrer Umgebung eine Konversion nicht mit Gewalt aufzwingen wollte, kam so offenbar zu der Ansicht, dass sich diese ablehnende Haltung zum Christentum durch die Einrichtung einer selbstständigen Kirchenorganisation in der Rus ändern könnte. Das Ersuchen um die Etablierung eines Bistums war höchstwahrscheinlich der Hauptgrund, weshalb sich Olga zum zweiten Mal nach Konstantinopel begab ${ }^{30}$. Diese Reise konnte im Jahr 955, wie in den russischen Annalen verzeichnet ist, oder auch später stattgefunden haben. Wenn dem so war, hatte die Fürstin mit ihren Plänen am Kaiserhof keinen Erfolg. Es scheint, dass der byzantinische Hof noch nicht bereit war, Kiew in dieser Angelegenheit entgegen zu kommen. Dem deutschen Slawisten Ludolf Müller zufolge herrschte in Konstantinopel die Befürchtung, wenn man der gerade getauften Rus entgegenkommen würde, dass dies weitere Völker dazu veranlassen würde, mehr zu fordern, als Byzanz ihnen zu geben bereit war ${ }^{31}$.

Fürstin Olga wandte sich gewisse Zeit nach ihrer Rückkehr in die Rus an den Westen, an das ostfränkische Reich. František Dvorník zufolge konnte sie hierzu von den Warägern inspiriert worden sein, die sich in Schweden mit der westlichen Kirchenorganisation bekannt gemacht hatten ${ }^{32}$. Interessant ist, meint der französische Mittelalterforscher

Ende des 11. Jahrhunderts, die Nestorchronik wurde erst im ersten Viertel des 12. Jahrhunderts verfasst.

27 Dies beweist auch der Umstand, dass ein Mitglied des Gefolges, das Olga nach Konstantinopel begleitete, ein Fürst mit Namen Gregorios war.

28 MÜLLER, Die Taufe Russlands, S. 86 war der Ansicht, dass Swjatoslaws Widerstand gegen das Christentum keine wesentliche Rolle spielte, denn Fürstin Olga hätte es mit der Christianisierung der Rus nicht ernst gemeint.

29 DVORNIK, Byzantine missions among the Slavs, S. $268 \mathrm{f}$.

30 Михаил Дмитриевич ПРИСЕЛКОВ, Очерки по церковной-политической истории Киевской Руси X-XII вв. С.-Петербург 1913, с. 10-12 (Mikhail Dmitrievich PRISELKOV, Ocherki po tserkovno-politicheskoi istorii Kievskoi Rusi X-XII vv. Sankt Peterburg 1913, S. 10 ff.).

31 MÚLLER, Die Taufe Russlands, S. 81; siehe auch ПАШУТО, Внешная политика Древней Руси, с. 66 (PASHUTO, Vneshnyaya politika Drevnei Rusi, S. 66).

32 DVORNIK, Byzantine missions among the Slavs, S. 269. 
Jean-Pierre Arrignon, dass sie sich nicht an den Papst wandte, wie dies in ihrer Lage durch üblich war, sondern an König Otto I. ${ }^{33}$. Jedoch bin ich der Meinung, dass sich Olga völlig analog wie in dem Fall verhielt, als sie ihren Wunsch an Byzanz richtete - aufgrund der dortigen Anordnung von weltlicher und kirchlicher Macht war es üblich, sich nicht nur mit Angelegenheiten profaner, sondern auch geistlicher Natur an den Kaiser zu wenden und nicht an den Patriarchen.

Die aus den Quellen gewonnenen Erkenntnisse können jedoch auch in einem etwas anderen Sinn und in anderen Zeitzusammenhängen ausgelegt werden. Nehmen wir an, dass Olga Konstantinopel nur einmal besucht hat, und zwar zu Beginn ihrer Herrschaftszeit, als sie noch Heidin war. Später empfing sie die Taufe und entschied sich, in der Rus eine selbstständige Kirchenorganisation gründen zu lassen, um so die Befürchtungen ihrer Umgebung zu verringern, dass die Rus infolge ihrer Eingliederung in die byzantinische Kirchenorganisation zu abhängig von Byzanz wird. Deshalb wandte sie sich logischerweise mit ihrer Bitte um Einrichtung eines Bistums nicht an Konstantinopel, sondern ebenso wie ein Jahrhundert zuvor der bulgarische Khan Boris an den lateinischen Westen ${ }^{34}$.

Im Jahr 959 kamen Abgesandte der Fürstin Olga ins Westreich zu Otto I., ,und baten ihn unaufrichtig, wie sich später zeigte, er möge ihrem Volk einen Bischof und Priester entsenden," vermerkte der Fortsetzer des Chronisten Regino von Prüm Adalbert ${ }^{35}$. Der König wünschte sich, die Zuständigkeitssphäre der Frankenkirche nach Osten auszudehnen und wollte zugleich vermittels des Christentums auch seinen politischen Einfluss erweitern. Olgas Bitte bot ihm die Gelegenheit, diesen Plan zu verwirklichen ${ }^{36}$. Deshalb zeigte er eine weitaus größere Bereitschaft als der byzantinische Kaiser, ihr entgegenzukommen und in der Rus eine eigenständige Kirchenorganisation zu etablieren. Er ließ den Mönch Libutius aus dem Albankloster in Mainz zum Bischof der Rus weihen und entsandte ihn nach Kiew. Den Geistlichen hielten jedoch Verzögerungen auf, so dass seine Abreise wiederholt verschoben wurde. Wahrscheinlich ist, dass er erkrankte, denn im Februar 961 starb er. Nach Kiew wurde dann „mit Ehrungen“ der spätere Chronist Adalbert entsandt, ein Mönch des Klosters St. Maximin in Trier, mit mehreren Priestern. Die Mission kam jedoch zu spät an ihrem Bestimmungsort an und „der für die Rus ernannte Bischof“ kehrte im folgenden Jahr ins Reich zurück, „denn er hatte nichts von dem erreicht, weshalb er entsandt worden war, und sich von der Vergeblichkeit seiner Bemühungen überzeugt. Einige [seiner Begleiter] wurden auf dem Rückweg aus Kiew erschlagen, er selbst rettete sich nach großen Entbehrungen", berichtete er später in seiner Chronik $^{37}$. Der Grund für Adalberts Misserfolg liegt auf der Hand. Zu der Zeit, als man im Reich die Entsendung der Mission in die Rus vorbereitete, wurde Olga auf dem Thron

33 Жеан-Пауль Ариньон, Международные отношения Киевской Руси в середине Х в. и крещение княгини Ольги, в: Византийский временник 41 (1980), с. 122 (Zhan-P’er Arinon, Mezhdunarodnye otnosheniya Kievskoi Rusi v seredine X v. i kreshchenie knyagini Olgi, in: Vizantiiskii vremennik 41 [1980], S. 122).

34 Arnold ANGENENDT, Mission zwischen Ost und West, in: Millenium Russiae Christianae, S. 22.

35 Der Fortsetzer Reginos (Adalberti) Continuatio Reginonis, hg. von Friedrich KURZE, in: Reginonis abbatis Prumiensis Chronicon cum continuatione Treverensi (MGH Scriptores rerum Germanicarum in usum scholarum separatim editi. Bd. 50). Hannover 1890, S. 170.

36 PADBERG, Christianisierung im Mittelalter, S. 133.

37 Continuatio Reginonis, S. 172. 
von ihrem Sohn Swjatoslaw abgelöst, und dieser hegte gegenüber dem Christentum starken Widerwillen. Das meinte Adalbert wahrscheinlich, als er von dem unaufrichtigen Verhalten der russischen Abgesandten sprach. Obwohl Otto I., der inzwischen zum römischen Kaiser gekrönt worden war, und wahrscheinlich auch der Papst bereit waren, der zukünftigen russischen Kirche mehr Selbstständigkeit als Byzanz zu gewähren, wurden ihre Pläne durchkreuzt, da der Großteil der Elite im sich formierenden russischen Staat noch nicht bereit war, das Christentum anzunehmen. Trotzdem ernannte Otto I. im Jahr 968 Adalbert zum ersten Erzbischof in Magdeburg und seine Hauptaufgabe wurde die Christianisierung der Slawen hinter den Ostgrenzen des Reichs. Dies war eine klare Demonstration, die den herrschenden Kreisen des byzantinischen Reichs andeuten sollte, dass der Befugnisbereich dieses Erzbistums auch das Land der Rus umfass ${ }^{38}$. Übrigens vergaß der Kaiser nicht, in der Ernennungsurkunde zu erwähnen, dass Adalbert ursprünglich dazu bestimmt war, Bischof der Rus zu werden ${ }^{39}$.

Erfolg hatte erst die vierte Christianisierungsetappe der Rus, die auf Anregung von Fürst Wladimir I. dem Heiligen erfolgte. Es ist jedoch nicht ausgeschlossen, dass bereits sein Bruder Jaropolk ein Christ war, der 972 nach seinem Vater Swjatoslaw den Thron bestieg und bis 980 herrschte, als er infolge eines Konflikts mit Wladimir getötet wurde. Aus Sicht des langfristigen Christianisierungsprozesses in der Rus handelt es sich nur um eine Episode, um einige kurze und nur schwer zu interpretierende Erwähnungen in den Quellen. Wenn Jaropolk jedoch wirklich Christ war, empfing er die Taufe höchstwahrscheinlich aus dem Westen, deshalb können wir diese Episode nicht übergehen. Die Nikonchronik enthält zum Jahr 979 einen einzigen und überaus kurzen Satz über päpstliche Gesandte, die aus Rom zum Fürsten Jaropolk kamen ${ }^{40}$. Dem russischen Historiker Oleg Mikhailovich Rapov zufolge konnte dies nur dann geschehen sein, falls Jaropolk Interesse am Christentum gezeigt hatte ${ }^{41}$. Diese Auslegung wird jedoch dadurch kompliziert, dass die Nikonchronik erst im 16. Jahrhundert verfasst wurde und dass ihre Angaben weder in den älteren russischen Annalen noch in Quellen westlichen Ursprungs überprüft werden können. Andererseits handelt es sich um eine einzigartige Quelle nicht nur für die zeitgenössische, sondern auch für die ältere Geschichte, die viele originale Angaben enthält. Dem Verfasser standen zahlreiche heute nicht mehr erhaltene Schriftstücke zur Verfügung und da er der Metropolit Daniil selbst gewesen sein konnte, hätte er auch Zugang zum Archiv des Metropolitenamtes gehabt. Hier konnte er zum Beispiel eine päpstliche Bulle gefunden haben, die die erwähnte Ankunft der päpstlichen Gesandtschaft in Kiew

38 Jukka KORPELA, „I krestiša kosti eju“: zur Vorgeschichte des Märtyrerkults von Boris und Gleb, in: Jahrbücher für Geschichte Osteuropas 46/2 (1998), S. 165.

39 Die Urkunden Konrads I., Heinrichs I. und Ottos I., hg. von Theodor SICKEL (MGH Die Urkunden der deutschen Könige und Kaiser. Bd. 1). Hannover 1879-1884, S. 502 (Nr. 366).

40 Михаил Николаевич ТИХОМИРОВ (сост.), Летописный сборник, именуемый Патриаршею или Никоновскую летописью. Москва 1965, с. 39 (Mikhail Nikolaevich TIKHOMIROV [Hg.], Letopisnyi sbornik, imenuemyi Patriarsheyu ili Nikonovskoi letopis'yu. Moskva 1965, S. 39).

41 Олег Михайлович РАПОВ, Официальное крещение Руси в конце Х в., в: Андрей Дмиртиевич Сухов (ред.), Введение христианства на Руси. Москва 1987, с. 102 (Oleg Mikhailovich RAPOV, Ofitsial'noe kreshchenie Rusi v kontse X v., in: Andrei Dmitrievich Sukhov [Hg.], Vvedenie khristianstva na Rusi. Moskva 1987, S. 102). Dem russischen Historiker Gennadii Grigor'evich LITAVRIN zufolge war es logisch, dass Jaropolk Gegenstand des Missionsinteresses des Papstes wurde, denn er engagierte sich politisch im katholischen Westen. ЛИТАВРИН, Византия Болгария, Древняя Русь, c. 90-91 (LITAVRIN, Vizantiya, Bolgariya, Drevnyaya Rus', S. 90 f.). 
betraf. Aufgrund des Mangels an Quellen bleibt jedoch die Hypothese über Jaropolks Taufe eine reine Spekulation, wie der finnische Historiker Jukka Jari Korpela konstatierte, obwohl er in seiner Abhandlung „I krestiša kosti eju“. Zur Vorgeschichte des Märtyrerkults von Boris und Gleb interessante, wenn auch indirekte Beweise dafür anbot, dass der Fürst tatsächlich Christ geworden war ${ }^{42}$. Zu diesem Schluss kam auch der russische Historiker Aleksandr Vasilevich Nazarenko ${ }^{43}$.

Von Jaropolks Kontakten mit der westlichen lateinischen Welt zeugt eine Eintragung in den Annalen des Lampert von Hersfeld. Im Jahr 973 entschied sich Kaiser Otto I., das Osterfest in Quedlinburg zu begehen, wo er Gesandtschaften aus verschiedenen Ländern empfing, die reiche Geschenke brachten, unter anderem auch aus der Rus ${ }^{44}$. Kurz darauf starb er und der Herzog von Bayern Heinrich II. der Zänker focht die Erbrechte seines Nachfolgers Otto II. an, wobei er sich auf eine Koalition mit den Herrschern von Böhmen, Polen und Dänemark stützte. Der junge König brauchte Verbündete, und deshalb wandte er sich an Jaropolk, denn bereits einige Jahre zuvor waren Kontakte zur Kiewer Rus angeknüpft worden. Im Jahr 976 oder 977 schloss er mit dem russischen Fürsten einen Bündnisvertrag, der durch Jaropolks Heirat mit der Enkelin Kaiser Ottos I. Richlint bekräftigt werden sollte. Die notwendige Voraussetzung des Bundes mit einer christlichen Prinzessin musste selbstverständlich sein, dass sich der bislang heidnische Bräutigam taufen ließ. So erklärte der deutsche Slawist Ludolf Müller Jaropolks Motivierung, die Taufe zu empfangen ${ }^{45}$. Zur Eheschließung kam es nicht mehr, denn Jaropolk wurde getötet. Nach der Ansicht einiger Historiker gerade deshalb, weil er mit dem Christentum sympathisierte ${ }^{46}$. Hatte er sich aber zuvor noch taufen lassen? Wurden ihm vielleicht die Sakramente der Taufe von einem der Geistlichen erteilt, die als Mitglieder der päpstlichen Gesandtschaft nach Kiew gereist waren? Diese Fragen können wir nicht mit Sicherheit beantworten. Wir können nur konstatieren, dass das Bündnis mit Kaiser Otto I. und die geplante Eheschließung für Jaropolk der Impuls zur eventuellen Annahme des Christentums sein konnten. Vergessen wir jedoch auch nicht, dass er am

${ }^{42}$ KORPELA, „I krestiša kosti eju“, S. 163-176. Korpela erklärte auch, weshalb die Nestorchronik keine Angaben über Kontakte mit dem westlichen Kaiserhof, der päpstlichen Abordnung und Jaropolks Taufe enthält. Am Text wurde ständig gearbeitet und seiner Meinung nach erfolgten die späteren Änderungen (nach 1054) im Geist einer Neigung zur Ostkirche. Deshalb war es nicht wünschenswert, Kontakte der russischen Fürsten mit den christlichen Zentren des lateinischen Westens zu erwähnen. Siehe auch ПАШУТО, Внешная политика Древней Руси, с. 75 (PASHUTO, Vneshnyaya politika Drevnei Rusi, S. 75).

43 Александр Васильевич НАЗАРЕНКО, Рус и Германия в IX-X вв., в: Древнейшие государства Восточной Европы 1 (1994), с. 99 (Aleksandr Vasilevich NAZARENKO, Rus' i Germaniya v IX-X vv., in: Drevneishie gosudarstva Vostochnoi Evropy 1 (1994), S. 99). Direkte Zeugnisse von Jaropolks Taufe in den russischen Chroniken zu finden versuchte Алексей Сергеевич ШАВЕЛЬЕВ, Летописные известия о крещении Ярополка Святославича, в: Вестник Российского государственного гуманитарного университета 12 (2011), с. 78-87 (Aleksei Sergeevich SHAVELEV, Letopisnye izvestiya o kreshchenii Yaropolka Svyatoslavicha, in: Vestnik Rossiiskogo gosudarstvennogo gumanitarnogo universiteta 12 (2011), S. 78-87).

44 Lamberti Hersfeldensis Annales, hg. von Oswald HOLDER-EGGER (MGH Scriptores rerum Germanicarum in usum scholarum separatim editi. Bd. 38). Hannover 1874, S. 20.

45 MÜLlER, Die Taufe Russlands, S. 91; Jukka KORPELA, Prince, Saint and Apostle - Prince Vladimir Svjatoslavič of Kiev: His Posthumous Life, and the Religious Legitimization of the Russian Great Power. Wiesbaden 2001, S. 77 f. Zum gleichen Schluss kam auch Александр Васильевич НАЗАРЕНКО, Рус и Германия в 70-е годы X века, в: Russia medievalis 6/1 (1987), c. $62-89$ (Aleksandr Vasilevich NAZARENKO, Rus' i Germaniya v 70-e gody X veka, in: Russia medievalis 6/1 (1987), S. 62-89).

46 РАПОВ, Официальное крещение Руси, с. 102 (RAPOV, Ofitsialnoe kreshchenie Rusi, S. 102). 
Hof seiner bereits christlichen Großmutter Fürstin Olga aufgewachsen warr ${ }^{47}$, und dass er zweifellos viel öfter in ihrer Gesellschaft war als in der seines Vaters, des heidnischen Kriegers Swjatoslaw, der fast seine gesamte Herrschaftszeit auf langwierigen Kriegszügen verbrachte. Die Fürstin Olga konnte ihren Enkelsohn zumindest dazu inspiriert haben, die Beziehungen mit dem westlichen Kaiser aufrecht zu erhalten, zu denen ihre Gesandtschaft den Impuls gegeben hatte.

Jaropolks Vater Swjatoslaw war ein eingefleischter Heide, das Christentum imponierte ihm nicht, später widmete er seine Sympathien dem Islam. Ein gewisser Teil seines Hofes, vor allem sein Gefolge, stimmt ihm hierin zweifellos zu. Die Lage in der Rus änderte sich jedoch mit der Zeit. Die Entwicklung des frühen russischen Staates, der sich um das Kiewer Zentrum formierte, erreichte eine höhere Stufe der Staatsbildung, die ideologisch besser von einer monotheistischen Religion reflektiert wurde. Nicht weniger wichtig war auch der Umstand, dass die heidnische Kiewer Rus im christlichen Europa allmählich in Isolierung geriet. Dessen musste sich zweifellos mit der Zeit auch Fürst Wladimir bewusst werden, der nach Jaropolks Tod im Jahr 980 den Kiewer Thron bestieg. Deshalb entschloss er sich, die Situation grundsätzlich zu ändern. Seine Wahl fiel auf das Christentum östlichen Ritus, das er offiziell als Herrscher des Landes annahm und als Staatsreligion einführte. Dies stellte die vierte und letzte Christianisierungsphase der Rus dar.

Es scheint völlig natürlich zu sein, dass sich Wladimir entschied, die Taufe gerade aus Byzanz zu empfangen. Zu seinen Gunsten sprachen die geografische Nähe und die langjährigen Beziehungen der sich formierenden russischen Gesellschaft zum byzantinischen Milieu, dessen kulturellem und geistlichem Einfluss sie sich seit den ersten Kontakten im Jahr 860 geöffnet hatte. Nach der Nestorchronik war Wladimirs Weg zum neuen Glauben jedoch nicht geradlinig. Zu Beginn seiner Herrschaftszeit dachte er überhaupt nicht an eine Annahme des Christentums und konnte sich das auch nicht erlauben, denn in seinem Gefolge konnten immer noch die heidnischen Kämpfer in der Überzahl sein, die Jaropolk gerade wegen dessen Sympathien für das Christentum verraten hatten ${ }^{48}$.

Der Chronist berichtet, wie sich Wladimir nach seiner Thronbesteigung bemühte, eine Art heidnischen Pantheon einzurichten ${ }^{49}$, und als diese eigenartige Reform der heidnischen Kulte nicht Fuß fasste, ließ sich der Fürst über die Bekenntnisse der Wolgabulgaren, der chasarischen Juden, der Deutschen ${ }^{50}$ und Griechen belehren. Diese Erzählung stützt sich zweifellos auf eine historische Grundlage, denn der russische Staat formierte sich in der Nachbarschaft der bulgarischen Muslime, der Chasaren, deren Elite sich zum Judentum bekannte, sowie in ständigen Kontakt mit dem orthodoxen Byzanz ${ }^{51}$. Belehrt durch die Erfahrungen seiner Großmutter Olga, musste sich der Fürst auch bewusst sein, dass er das Christentum nicht nur vom byzantinischen Osten empfangen konnte, sondern auch vom lateinischen Westen, und dass er sich um eine selbstständige Kirchenorganisation bemühen sollte. Der deutsche Forscher Hartmut Rüss bezweifelte,

47 Повесть временных лет, с. 32 (Povest' vremennykh let, S. 32).

48 RÜSS, Das Reich von Kiev, S. 303 f., Anm. 21; РАПОВ, Официальное крещение Руси, с. 102 (RAPOV, Ofitsialnoe kreshchenie Rusi, S. 102); siehe auch PADBERG, Christianisierung im Mittelalter, S. 133.

49 Повесть временных лет, с. 37 (Povest vremennykh let, S. 37).

50 Ebd., S. 39 f. Mit dem Begriff Deutsche werden hier Menschen bezeichnet, die aus dem Reich kamen, das heißt Christen des westlichen Ritus.

51 SHEPARD, Rus', S. 374 f. 
dass man in Kiew an einen Übergang zum Islam, zum jüdischen Glauben oder zum Katholizismus gedacht hätte und hält diese Episode für unglaubwürdig ${ }^{52}$, obwohl von einer Gesandtschaft Wladimirs zu den Muslimen, und zwar zum Herrscher des Reiches Choresmien, auch der arabische Schriftsteller Marwazi berichtet ${ }^{53}$. Die Frage, weshalb der Chronist die Episode in sein Werk aufgenommen hat, stellt er sich nicht. Reflektierte sie vielleicht entfernt die diplomatischen Aktivitäten, die sich zwischen Wladimir und dem byzantinischen Kaiser Basileios II. entfalteten und im Endergebnis zur Taufe der Rus führten, wie der tschechische Kirchenhistoriker Jan Blahoslav Lášek annimmt ${ }^{54}$ ? Meiner Meinung nach sollte sie eher die Vorteile des östlichen Christentums vor den sonstigen monotheistischen Religionen betonen ${ }^{55}$ und vermittels einer in gewissem Maß erdachten Geschichte die unbestreitbare Tatsache zum Ausdruck bringen, dass diese Religionen in der Rus nicht unbekannt waren.

Es gibt keinen Zweifel daran, dass das byzantinische Reich zum Anfang von grundsätzlicher Bedeutung für die Christianisierung der Rus war. An dieser Tatsache ändert auch der Umstand nichts, dass wir nicht genau zu bestimmen vermögen, wie konkret und in welcher Reihenfolge die einzelnen Ereignisse verliefen - damit meine ich die Eroberung von Chersones, die eigentliche Taufe von Wladimir und seine Heirat mit der byzantinischen Prinzessin Anna Porphyrogenneta - und vor allem wissen wir nicht mit Gewissheit, ob der Impuls zu Wladimirs Taufe von der russischen oder der byzantinischen Seite ausging. Persönlich neige ich zu der Ansicht, dass es die Kaiser von Byzanz Basileios II. und Konstantin VIII. waren, die sich an den russischen Fürsten mit einer dringenden Bitte um militärische Unterstützung wandten. Der entscheidende Impuls zur Christianisierung wurde so das politische Geschehen ${ }^{56}$, wie im Fall von Bulgarien. Die Karten waren jedoch umgekehrt vergeben und Wladimir befand sich in der entgegengesetzten Stellung wie der besiegte bulgarische Khan Boris. Deshalb konnte er sich erlauben, bestimmte Forderungen zu stellen. So erhielt er nicht nur das, was Konstantin VII. der Fürstin Olga verwehrt hatte, das heißt eine selbstständige Kirchenorganisation für die Rus - obwohl dies aus der Sicht von Konstantinopel nicht eilte und es dazu erst später gekommen sein konnte - sondern außerdem für sich noch eine hochgeschätzte Braut aus der Kaiserdynastie. Das bedeutete für einen barbarischen Herrscher, der als einer der letzten in Europa auf der Verehrung heidnischer Götter verharrte, einen wirklich ungemeinen Prestigegewinn. Damit es jedoch zu der Eheschließung kommen konnte, musste Wladimir den Glauben seiner zukünftigen Gattin annehmen und ein Christ werden.

Das Angebot, mit dem eine kaiserliche Gesandtschaft zum Kiewer Hof reiste, kam Wladimir auf höchste gelegen, und zwar nicht nur, falls er bereits über die Annahme des östlichen Christentums nachgedacht hatte. Sollte er immer noch geglaubt haben, dass es ihm gelingt, eine Art heidnischen Pantheon zu schaffen, oder - wir sollten auch diese Variante zulassen - zwischen Christentum, Islam und Judaismus schwanke, konnte

52 RÜSS, Das Reich von Kiev, S. 306.

53 MARWAZI, Die Russen, in: Arabische Quellen zur Christianisierung Rußlands, S. 23 ff. Marwazi nennt ganz andere Gründe für die Reise der Kiewer Gesandtschaft zum Hof des choresmischen Herrschers als der Kiewer Chronist.

54 Jan Blahoslav LÁŠEK, Počátky křest’anství u východních Slovanů. Praha 1997, S. 147.

55 George P. MAJESKA, Russia: the Christian Beginnings, in: Albert Leong (Hg.), Millenium: Christianity and Russia, A.D. 988-1988. New York 1990, S. $21 \mathrm{f}$.

56 POPPE, The Political Background to the Baptism of Rus', S. 197-200, 224-244. 
ihm das Treffen mit den byzantinischen Gesandten einen wichtigen Impuls geben. Aus diesem Blickwinkel ist es weder wichtig, ob ihm die Kaiser die Hand der byzantinischen Prinzessin anboten oder ob der Fürst selbst darum ersuchte, noch, weshalb es eigentlich zur Eroberung von Chersones $\mathrm{kam}^{57}$. Wesentlich ist, dass die politischen Absichten des Hofes in Konstantinopel in diesem Augenblick mit den Interessen des Kiewer Fürsten in Einklang lagen, den zur Annahme des neuen Glaubens weder eine persönliche Motivation brachte noch die geistliche, moralische oder kultische Überlegenheit der christlichen Religion, sondern reife politische Überlegung. Deshalb war nun die Konversion zum Christentum unumkehrbar ${ }^{58}$. Der russische Herrscher wurde Ende der achtziger Jahre des 10. Jahrhunderts offiziell getauft, mit ihm nahmen die Taufe zweifellos auch sein Gefolge und die Bevölkerung von Kiew an. In die Rus kamen griechische Missionare und das ostslawische Milieu öffnete sich einem breiten Einfluss der Ostkirche ${ }^{59}$.

Wladimir beschränkte seine Kontakte mit den Christen jedoch nicht nur auf das byzantinische Reich und sandte einen Bericht über die Annahme des Christentum in der Rus nicht nur nach Jerusalem, Ägypten und Babylon, womit offenbar die Patriarchen in Alexandria und Antiochien gemeint sind, sondern auch an den Papst in Rom ${ }^{60}$. Außerdem tauschte er in den neunziger Jahren mehrere Gesandtschaften mit dem Papst aus ${ }^{61}$, wobei die erste von ihnen bereits 988 nach Chersones gereist sein soll ${ }^{62}$. Das Problem ist, dass wir dies erst aus Quellen erfahren, die aus dem 16. Jahrhundert stammen, und zwar aus der Nikonchronik und einem unter dem Namen Stepennaya kniga bekannten Werk, das wir als ersten Versuch einer systematischen Darlegung der russischen Geschichte bezeichnen können. Auch diese Angaben lassen sich nicht in anderen Quellen nachprüfen, ebenso wie dies beim Empfang der päpstlichen Abgesandten durch Jaropolk der Fall war.

Die Mitteilungen, dass in Kiew eine Gesandtschaft vom Papst eintraf oder umgekehrt, dass Wladimir seine Boten nach Rom entsandte, sind überaus kurz und deuten in keiner Weise an, was das Ziel dieser Missionen war. Nur zum Jahr 988 informiert der Verfasser, dass Gesandte aus Rom in Chersones eintrafen und für den Fürst Heiligenreliquien mitbrachten. Dies ruft eine Reihe von Fragen auf, zum Beispiel die, weshalb die päpstliche Gesandtschaft gerade nach Chersones reiste, denn in Rom konnte man schwerlich wissen, dass sich Wladimir zu der Zeit eben in dieser Stadt befand. Der tschechische

57 Alex M. FELDMAN, How and Why Vladimir Besieged Cherson: an Inquiry into the Latest Research on the Chronology of the Conversion of Vladimir, 987-989 CE, in: Byzantinoslavica, 73/1-2 (2015), S. $145-170$.

58 POPPE, The Political Background to the Baptism of Rus', S. 243; DERS., Das Reich der Rus' im 10. und 11. Jahrhundert: Wandel der Ideenwelt, in: Jahrbuch für Geschichte Osteuropas 28 (1980), S. 337.

59 Jukka Korpela ist trotz dieser allgemein vertretenen Ansicht der Meinung, dass die Griechen in der russischen Gesellschaft keine dominierende Rolle spielten, und dies auch nicht unter den Geistlichen. Vgl. Beiträge zur Bevölkerungsgeschichte und Prosopographie der Kiewer Rus' bis zum Tode von Vladimir Monomah. Jyväskylä 1995, S. 121.

60 Летописный сборник, именуемый Патриаршею или Никоновскую летописью, с. 68 (Letopisnyi sbornik, imenuemyi Patriarsheyu ili Nikonovskoi letopis'yu, S. 68); Платон Григорьевич ВАСЕНКО (сост.), Книга степенная царского родословия (1-10 степени грани). Санктпетербургь 1908, c. 127 (Platon Grigor'evich VASENKO [Hg.], Kniga stepennaya tsarskogo rodosloviya 1-10 stepeni grani. Sanktpeterburg 1908, S. 127).

61 Летописный сборник, именуемый Патриаршею или Никоновскую летописью, с. 64, 65 (Letopisnyi sbornik, imenuemyi Patriarsheyu ili Nikonovskoi letopis'yu, S. 64 f.).

62 Летописный сборник, именуемый Патриаршею или Никоновскую летописью, с. 103 (Letopisnyi sbornik, imenuemyi Patriarsheyu ili Nikonovskoi letopis'yu, S. 103). 
Kirchenhistoriker František Dvorník erklärt dies damit, dass es sich wahrscheinlich nicht um Boten des Papstes Johannes XV. handelte, sondern der Regentin Theophanu, die sich damals in Rom aufhielt. Die Kaiserin, die sich angeblich regelmäßig über das Geschehen in Konstantinopel berichten ließ, erfuhr von der Heirat Prinzessin Annas und sandte ihr als Hochzeitsgeschenk Reliquien ${ }^{63}$. Dieser Auslegung könnten wir nur dann zustimmen, wenn die Gesandtschaft ihr Ziel in Kiew und nicht auf der Krim hatte. In diesem Fall ergibt es keinen Sinn, auch wenn wir jeder beliebigen Version der Geschichte über Wladimirs Feldzug gegen Chersones beipflichten. Ob er nun zuerst die Stadt erobert und erst dann bei den byzantinischen Kaisern um die Hand ihrer Schwester angehalten hat, oder ob er deshalb gegen die Krim gezogen ist, um sie zu zwingen, den militärischen Bündnisvertrag einzuhalten, den sie zuvor geschlossen hatten, oder ob er Chersones nach der wahrscheinlichsten Version als Basileios Verbündeter überfallen hat ${ }^{64}$. In all diesen Fällen würde Chersones zufällig zum Ort der Heirat werden und Theophanu hätte nicht rechtzeitig davon erfahren können, um die Gesandtschaft mit den Geschenken dorthin zu schicken.

Eine logischere, wenn auch wiederum spekulative Erklärung bot der amerikanische Forscher George P. Majeska an. Er ging von der Annahme aus, dass Byzanz nicht sofort nach Wladimirs Taufe eine selbstständige Kirchenorganisation in der Rus einrichtete, auch wenn zum Beispiel Ludolf Miller annimmt, dass dem so war ${ }^{65}$. Das würde jedoch nicht der üblichen byzantinischen Kirchenpraxis entsprechen ${ }^{66}$. Die Quellen lassen uns im Dunkeln darüber, welche Schritte der Hof in Konstantinopel in dieser Richtung unternahm. Majeskas Hypothese nimmt an, dass Fürst Wladimir mit dieser Lösung nicht zufrieden war und sich deshalb an den Papst wandte. Er verhielt sich ebenso wie seine Großmutter Olga (und ein Jahrhundert zuvor auch der bulgarische Khan Boris) und verhandelte über die Schaffung einer selbstständigen Kirchenorganisation mit der lateinischen Westkirche. Oder er bemühte sich zumindest, durch Verhandlungen mit dem Papst Druck auf Byzanz auszuüben, damit man sie von dort aus in der Rus einrichtet. Deshalb kam die päpstliche Gesandtschaft zu ihm nach Chersones und als er in die Rus zurückkehrte, dann noch einmal nach Kiew. Der Papst war jedoch nicht bereit, der jungen russischen Kirche mehr Unabhängigkeit anzubieten als Konstantinopel, und so blieb diese unter der Jurisdiktion des Patriarchen von Konstantinopel ${ }^{67}$, der schließlich in Kiew eine Metropolie einrichtete. Wann dies geschah, wissen wir allerdings nicht genau.

Eine weitere Gesandtschaft aus Rom erschien im Jahr 1000 in der Rus. Versuchte vielleicht die päpstliche Kurie noch einmal, den Fürsten Wladimir zu bewegen, ihre kirchliche Oberherrschaft anzunehmen? Oder ging es um eine Initiative von Kaiser Otto III., wie František Dvorník urteilt? Der junge Herrscher bemühte sich nach dessen Ansicht, die Kiewer Rus in das Programm renovatio imperii einzubeziehen und aus ihr einen Bestandteil des römischen Imperiums zu machen, wie er dies bereits im Fall des polni-

${ }^{63}$ Francis DVORNIK, The Making of Central and Eastern Europe. London 1949, S. 174.

${ }^{64}$ Mit der Theorie, dass die Eroberung von Chersones durch den Kiewer Fürsten Wladimir I. Teil einer Vereinbarung mit Kaiser Basileios II. war, traten Ludolf MÜLLER, Die Taufe Rußlands, S. 111, 113 oder Andrzej POPPE, The Political Background to the Baptism of Rus', S. 198, 238 f. auf.

65 MÜLLER, Die Taufe Russlands, S. 106.

${ }_{66}$ DVORNIK, The Making of Central and Eastern Europe, S. 177.

${ }^{67}$ MAJESKA, Russia: the Christian Beginnings, S. 24; siehe ANGENENDT, Mission zwischen Ost und West, S. 22. 
schen Fürstentums getan hatte. Deshalb entsandte er im Jahr 1000 in Zusammenarbeit mit dem Papst eine Gesandtschaft nach Kiew. Im folgenden Jahr kamen russische Gesandte nach Rom und brachten offenbar Wladimirs Antwort mit, deren Inhalt wir nicht kennen. Die weiteren Pläne wurden vom Tod des Kaisers durchkreuzt ${ }^{68}$. Erwähnungen von Kontakten des Fürsten Wladimir zu Rom gelangten höchstwahrscheinlich in die ursprünglichen Texte der Annalen, wurden jedoch mit der Zeit unerwünscht und die Zusammensteller der Chroniken, orthodoxe Geistliche, sorgten dafür, dass sie aus den Annalen verschwanden. Ebenso finden wir in ihnen weder Angaben über die Gesandtschaft der Fürstin Irina an den Kaiserhof von Otto I. noch über Beziehungen des Fürsten Jaropolk zum lateinischen Westen.

Der sich formierende russische Staat lag nicht auf ursprünglich römischem Gebiet wie Bulgarien, aber seine Wirtschaft und die Stellung der herrschenden Schicht waren bis ins 12. Jahrhundert lebenswichtig abhängig vom Handel mit Byzanz. Die russischen Kaufleute, die ins byzantinische Reich reisten, waren dort dem Einfluss der griechischen Kultur und des Alltagslebens der Byzantiner ausgesetzt, dessen Niveau zweifellos um ein Vielfaches die Lebensverhältnisse in der Rus überstieg. Es ist daher nur natürlich, dass sie von hier auch den christlichen Glauben annahmen. Eine Sache war jedoch die Annahme des Christentums, eine andere die Etablierung einer Kirchenorganisation und deren Eingliederung in die bestehende Struktur der christlichen Kirche, die dem betreffenden Land auch bestimmte kirchlich-politische Bindungen brachten. Die Kiewer Herrscher befanden sich in Bezug auf Byzanz in einer völlig anderen Stellung als die Bulgaren, oder als die Mährer gegenüber dem westlichen Kaiserreich beziehungsweise dem ostfränkischen König. In dem Augenblick, als man in der Rus an die Einrichtung eines Bistums oder Erzbistums zu denken begann, wandte man sich jedoch mit dieser Bitte nicht nur an Konstantinopel, sondern auch an den Westen, an den Kaiser oder gegebenenfalls an den Papst. Dies wissen wir von Fürstin Olga und können es auch bei Wladimir I. vermuten. Außerdem steht uns ein kurzer Bericht über Kontakte mit dem Kaiser zur Verfügung, die vom Fürsten Jaropolk, Wladimirs Stiefbruder und Vorgänger auf dem Kiewer Thron, angeknüpft wurden. Die unzureichende Quellenbasis erlaubt uns jedoch nicht, alle Fragen zu beantworten, die in diesem Zusammenhang aufgeworfen werden könnten.

\section{Danksagungen}

Diese Studie ist im Rahmen des Universitätsprogramms PROGRES Q 09: Geschichte der Schlüssel zum Verständnis der globalisierten Welt erschienen.

\section{LITERATURVERZEICHNIS}

\section{Quellen}

Constantini Porphyrogeniti De cerimoniis aulae Byzantinae, in: Jacques-Paul MIGNE (Hg.), Patrologia Graeca. Bd. 112. Turnholt 1897, col. 1047-1054.

Encyklika epistola ad archiepiscopales thronos per Orientem obtinentes, in: Jacques-Paul MIGNE (Hg.), Patrologia Graeca. Bd. 102. Turnholt 1900, col. 735-738.

${ }_{68}$ DVORNIK, The Making of Central and Eastern Europe, S. 179. 
Der Fortsetzer Reginos (Adalberti) Continuatio Reginonis, hg. von Friedrich KURZE, in: Reginonis abbatis Prumiensis Chronicon cum continuatione Treverensi (MGH Scriptores rerum Germanicarum in usum scholarum separatim editi. Bd. 50). Hannover 1890, S. 154-179.

Ioannis Scylitzae synopsis historiarum, hg. von Hans THURN (Corpus Fontium Historiae Byzantinae. Series Berolinensis. Bd. 5). Berlin/New York 1973.

Платон Григорьевич ВАСЕНКО (сост.), Книга степенная изарского родословия (1-10 степени грани). Санктпетербургь 1908 (Platon Grigorevich VASENKO [Hg.], Kniga stepennaya tsarskogo rodosloviya 1-10 stepeni grani. Sanktpeterburg 1908).

Lamberti Hersfeldensis Annales, hg. von Oswald HOLDER-EGGER (MGH Scriptores rerum Germanicarum in usum scholarum separatim editi. Bd. 38). Hannover 1874.

MASÚDÍ, Bericht über die Slaven, in: Peter Kawerau (Hg.), Arabische Quellen zur Christianisierung Ruslands. Wiesbaden 1967.

Михаил Николаевич ТИХОМИРОВ (сост.), Летописный сборник, именуемый Патриаршею или Никоновскую тетописью. Москва 1965 (Mikhail Nikolaevich TIKHOMIROV [Hg.], Letopisnyi sbornik, imenuemyi Patriarsheyu ili Nikonovskoi letopis'yu. Moskva 1965).

Дмитрий Сергеевич ЛИХАЧЕВ - Варвара Павловна АДРИАНОВА-ПЕРЕТЦ (сост.) Повесть временных лет. Санкт Петерсбург 1996 (Dmitrii Sergeevich LIKHACHEV - Varvara Pavlovna ADRIANOVA-PERETTS [Hgg.], Povest' vremennykh let. Sankt Peterburg, 1996).

Theopfanes Continuatus, in: Jacques-Paul MIGNE (Hg.), Patrologia Graeca. Bd. 109. Paris 1863, col. 209-212.

Die Urkunden Konrads I., Heinrichs I. und Ottos I., hg. von Theodor SICKEL (MGH Die Urkunden der deutschen Könige und Kaiser. Bd. 1). Hannover 1879-1884.

\section{Literatur}

Arnold ANGENENDT, Mission zwischen Ost und West, in: Millenium Russiae Christianae, S. 3-23.

Жеан-Пауль АРИНЬОН, Международные отношения Киевской Руси в середине Х в. и крещение княгини Ольги, в: Византийский временник 41 (1980), с. 113-124 (Zhan-P’er Arinon, Mezhdunarodnye otnosheniya Kievskoi Rusi v seredine X v. i kreshchenie knyagini Ol'gi, in: Vizantiiskii vremennik 41 [1980], S. 113-124).

Nils BLOMKVIST - Stefan BRINK - Thomas LINDKVIS, The kingdom of Sweden, in: Berend (Hg.), Christianization and the Rise of Christian Monarchy, S. 176-179.

Владимир ДУХОПЕЛЬНИКОВ, Крещение Руси. Харков 2009 (Vladimir DUKHOPEL'NIKOV, Kreshchenie Rusi. Khar'kov 2009).

Francis DVORNIK, Byzantine missions among the Slavs: SS. Constantine-Cyril and Methodius. New Brunswick, NJ 1970.

Francis DVORNIK, The Making of Central and Eastern Europe. London 1949.

Michael FEATHERSTONE, Olga's Visit to Constantinople in De Cerimoniis, in: Revue de Etudes Byzantines 61 (2003), S. 241-251.

Alex M. FELDMAN, How and Why Vladimir Besieged Cherson: an Inquiry into the Latest Research on the Chronology of the Conversion of Vladimir, 987-989 CE, in: Byzantinoslavica, 73/1-2 (2015), S. $145-170$.

Manfred HELLMANN, Westeuropäische Kontakte der Alten Rus', in: Gerhard Bikrfellner (Hg.), Millenium Russiae Christianae: Tausend Jahre Christliches Rusland 988-1988. München/Wien 1993, S. 81-94.

Jukka KORPELA, „I krestiša kosti eju“: zur Vorgeschichte des Märtyrerkults von Boris und Gleb, in: Jahrbucher für Geschichte Osteuropas 46/2 (1998), S. 161-176.

Jukka KORPELA, Prince, Saint and Apostle - Prince Vladimir Svjatoslavič of Kiev: His Posthumous Life, and the Religious Legitimization of the Russian Great Power. Wiesbaden 2001.

Аполлон Григорьевич КУЗЬМИН, Сказание об апостоле Андрее и его место в Началной летописи, в: РЫБАКОВ (сост.), Летописи и хроники, с. 37-47 (Apollon Grigor’evich KUZ’MIN, Skazanie ob apostole Andree i ego mesto v Nachal'noi letopisi, in: RYBAKOV [Hg.], Letopisi i khroniki, S. 37-47).

Jan Blahoslav LÁŠEK, Počatky křestanství u vychodních Slovanů. Praha 1997.

Геннадий Григорьевич ЛИТАВРИН, Древняя Русь, Византия и Болгария в IX -X вв. Москва 1983, c. 30-67 (Gennadii Grigor'evich LITAVRIN, Drevnyaya Rus, Vizantiya i Bolgariya v IX -X vv. Moskva 1983, S. 30-67). 
Геннадий Григорьевич ЛИТАВРИН, Византия Болгария, Древняя Русь (IX-начало XII в). Спб. 2000 (Gennadii Grigor'evich LITAVRIN, Vizantiya, Bolgariya, Drevnyaya Rus' IX-nachalo XII v. Sankt-Peterburg 2000).

George P. MAJESKA, Russia: the Christian Beginnings, in: Albert Leong (Hg.), Millenium: Christianity and Russia, A.D. 988-1988. New York 1990.

Ludolf MÜLLER, Die Taufe Russlands: die Frühgeschichte der russischen Christen bis zum Jahre 988. München 1987.

Лудольф МЮЛЛЕР, Древнрусское сказание о хождении апостола Андрея в Киев и Новгород, Борис Александрович РЫБАКОВ (сост.), в: Летописи и хроники. 1974, с. 48-64 (Ludol'f MYULLER, Drevnerusskoe skazanie o khozhdenii apostola Andreya v Kiev i Novgorod, in: Boris Aleksandrovich RYBAKOV [Hg.], Letopisi i khroniki 1974, S. 48-64).

Александр Васильевич НАЗАРЕНКО, Еще раз о дате поездки княгини Ольги в Константинополь: Источниковедческие заметки, в: Древнейшие государства Восточной Европы. Москва 1995, c. 154-168 (Aleksandr Vasilevich NAZARENKO, Eshche raz o date poezdki knyagini Ol'gi v Konstantinopol': Istochnikovedcheskie zametki, in: Drevneishie gosudarstva Vostochnoi Evropy. Moskva 1994, S. 154-168).

Александр Васильевич НАЗАРЕНКО, Когда же княгиня Ольга ездила в Константинополь, в: Византийский временник 50 (1989), с. 66-83 (Aleksandr Vasil'evich NAZARENKO, Kogda zhe knyaginya Ol'ga ezdila v Konstantinopol', in: Vizantiiskii vremennik, 50 (1989), S. 66-83).

Александр Васильевич НАЗАРЕНКО, Рус и Германия в IX-Х вв., в: Древнейшие государства Восточной Европь 1 (1994) (Aleksandr Vasil'evich NAZARENKO, Rus' i Germaniya v IX-X vv., in: Drevneishie gosudarstva Vostochnoi Evropy 1 (1994)).

Александр Васильевич НАЗАРЕНКО, Рус и Германия в 70-е годы Х века, в: Russia medievalis 6/1 (1987), c. 62-89 (Aleksandr Vasilevich NAZARENKO, Rus' i Germaniya v 70-e gody X veka, in: Russia medievalis 6/1 (1987), S. 62-89).

Dmitri OBOLENSKY, Russia and Byzantium in the Mid-Tenth Century: the Problem of Baptism of Princess Olga, in: The Greek Orthodox Theological Review 28/2 (1983), S. 157-171.

Георгий Александрович ОСТРОГОРСКИЙ, Византия и киевская княгиня Ольга (Georgii Aleksandrovich OSTROGORSKII, Vizantiya i kievskaya knyaginya Ol'ga), in: To Honor of Roman Jakobson. Bd. 2. Hague/Paris 1967.

Lutz E. von PADBERG, Christianisierung im Mittelalter. Darmstadt 2006.

Владимир Терентьевыс̌ ПАШУТО, Внешная политика Древней Руси. Москва 1968, (Vladimir Terent'evich PASHUTO, Vneshnyaya politika Drevnei Rusi. Moskva 1968).

Andrzej POPPE, Once Again Concerning the Baptism of Olga, Archontissa of Rus', in: Anthony Cutler Simon Franklin (Hgg.), Homo Byzantinus: Papers in Honor of Alexander Kazhdan. Washington, DC 1992, S. 271-277.

Andrzej POPPE, The Political Background to the Baptism of Rus': Byzantine-Russian Relations between 986-989, in: Dumbarton Oaks Papers 30 (1976), S. 195-244.

Михаил Дмитриевич ПРИСЕЛКОВ, Очерко по иерковной-политической истории Киевской Руси X-XII вв. С.-Петербург 1913 (Mikhail Dmitrievich PRISELKOV, Ocherki po tserkovnopoliticheskoi istorii Kievskoi Rusi X-XII vv. Sankt-Peterburg 1913).

Omeljan PRITSAK, When and Where Was Ol'ga Baptized, in: Harvard Ukrainian Studies 9/1-2 (1985), S. 5-24.

Олег Михайлович РАПОВ, Официальное крещение Руси в конце X в., в: Андрей Дмиртиевич Сухов (ред.), Введение христианства на Руси. Москва 1987 (Oleg Mikhailovich RAPOV, Ofitsial'noe kreshchenie Rusi v kontse X v., in: Andrei Dmitrievich Sukhov [Hg.], Vvedenie khristianstva na Rusi. Moskva 1987).

Hartmut RÜSS, Das Reich von Kiev, in: Manfred Hellmann - Gottfried Schramm - Klaus Zernack (Hgg.), Handbuch der Geschichte Russlands. 1. Bd: Bis 1613 von der Kiever Reichsbildung bis zum Moskauer Zartum. Stuttgart 1981, S. 199-430.

Jonathan SHEPARD, Rus', in: Nora Berend (Hg.), Christianization and the Rise of Christian Monarchy: Scandinavia, Central Europe and Rus'c.900-1200. Cambridge 2007. 
Алексей Сергеевич ШАВЕЛЬЕВ, Летописные известия о крещении Ярополка Святославича, в: Вестник Российского государственного гуманитарного университета 12 (2011), с. 78-87 (Aleksei Sergeevich SHAVEL'EV, Letopisnye izvestiya o kreshchenii Yaropolka Svyatoslavicha, in: Vestnik Rossiiskogo gosudarstvennogo gumanitarnogo universiteta 12 (2011), S. 78-87).

Vladimír VAVŘíNEK, Cyril a Metoděj mezi Konstantinopoli a Římem. Praha 2013. 